\title{
José Nicolás de Azara, un icono del Grand Tour
}

\author{
JoRge García SÁNCHEZ* \\ Escuela Española de Historia y Arqueología en Roma \\ José Nicolás de Azara, a Grand Tour icon
}

\begin{abstract}
RESUMEN ABSTRACT
José Nicolás de Azara, bien conocido como Agente de Preces y ministro plenipotenciario ante la Santa Sede, fue tal vez la personalidad española de mayor influencia en los círculos intelectuales y artísticos de la Roma del siglo XVIII. Su asumida función de guía ilustrado y su vocación pedagógica para con los jóvenes viajeros lo convirtieron en un auténtico icono del Grand Tour.

PALABRAS CLAVE: Azara / siglo XVIII / Roma / Ilustración / José Nicolás de Azara, well known as Agente de Preces (Agent of Supplications) and ministro plenipotenciario (Plenipotentiary Minister) in the Holy See, was perhaps the most influential Spanish personality in the intellectual and artistic circles of Eighteenth-Century Rome. His wilful function of enlightened guide and his pedagogic attitude towards the young travellers made of him an authentic icon of the Grand Tour.

KEYWORDS:

Grand Tour Azara / 18th Century / Rome / Enlightenment / Grand Tour
\end{abstract}

\footnotetext{
* La redacción de este artículo ha sido posible gracias a una Beca Postdoctoral del Ministerio de Educación, Cultura y Deporte, que se disfruta actualmente en la Escuela Española de Historia y Arqueología en Roma (CSIC).

Doctor europeo por la Universidad Complutense de Madrid. Escuela Española de Historia y Arqueología. Via di Torre Argentina, 18. 00186 - Roma. e-mail: jorgegstg @gmail.com
} 
En la segunda mitad del siglo XVIII, cualquier viajero de origen británico que en su itinerario por la Campania se hubiese paseado entre las ruinas de Pompeya y Herculano, ascendido al inmortal Vesubio, o atravesado la gruta de Posilipo, no habría descuidado el presentar sus respetos a Sir William Hamilton (1730-1803), como si se tratara de uno más de los hitos de la visita del Grand Tour, un emblema de los ambientes culturales y de la buena sociedad napolitana. Hamilton, embajador de Su Majestad británica en Nápoles entre 1764 y 1800, desempeñó sus obligaciones diplomáticas en una de las ciudades italianas más apropiadas para desplegar dos de sus máximas pasiones, el coleccionismo de obras de arte antiguas y la investigación geológica ${ }^{1}$, que le valieron su ingreso en la Royal Society de Londres en 1766 y en la Society of Dilettanti en $1776^{2}$. Su colección de vasos griegos, publicada en 1766 por el francés d'Hancarville ${ }^{3}$, es solo una mínima parte del extraordinario repertorio de mármoles, bronces, piezas numismáticas, gemas y lienzos que atesoraba en sus villas de Posillipo y Portici, así como en su residencia napolitana. Los pinceles de Gavin Hamilton, uno de sus proveedores de antigüedades, Angelica Kauffman, Reynolds o Thomas Jones se pusieron a su servicio y al de su segunda esposa, la tantas veces retratada, y polémica Emma Hart, cuya belleza helénica, por cierto, no le pasó desapercibida ni siquiera al personaje en el que nos centraremos a continuación ${ }^{4}$.

Con estas pocas líneas sobre la figura de Hamilton hemos pretendido bosquejar el prototipo de una categoría de políticos ilustrados de la Europa de las Luces a la que perteneció el diplomático aragonés José Nicolás de Azara (17301804), marqués de Nibbiano, acaso la personalidad española de mayor influencia en los medios intelectuales y artísticos de la Roma del Settecento, a la que llegó en 1766 en calidad de Agente de Preces, y que sólo abandonaría en 1798, después de catorce años como ministro plenipotenciario de la monarquía borbónica ante la Santa Sede.

1 No tenemos más que recordar su obra sobre vulcanología de los Campi Phlegraei. Observations on the Volcanos of the Two Sicilies As They have been communicated to the Royal Society of London by Sir William Hamilton, K.B.F.R.S., His Britannic Majesty's Envoy Extraordinary, and Plenipotentiary at the Court of Naples. To wich, in Order to convey the most precise idea of each remark, a new and accurate Map is annexed, with 54 Plates illuminated, from drawings taken and colour'd after Nature, under the inspection of the Autor, by the Editor, Mr. Peter Fabris, Nápoles, 1776.

2 Carlo KNIGHT, «l luoghi di delizie di William Hamilton», Napoli Nobilissima, XX, 5-6 (1981), pp. 180190; del mismo autor, Hamilton a Napoli: cultura, svaghi, civiltà di una grande capitale europea, Nápoles, 2003; Gigliola PAGANO, G., y Vincenzo GIURA, L'Italia del secondo Settecento nelle relazioni segrete di William Hamilton, Horace Man e John Murray, Nápoles, 1997; y AA.VV., The Hamilton papers: carte donate alla Società Napoletana di Storia Patria, Nápoles, 1999.

3 Pierre François Hugues D'HANCARVILLE, Antiquités etrusques, grecques et romaines tirées du cabinet de M. Hamilton envoyé extraordinaire de S. M. Britannique en cour de Naples, Nápoles, 1766-1767.

4 «De Nápoles cuentan millares de anécdotas extravagantes y curiosas. La reina parece que se ha llevado a tierra a la Hamilton, Milady que yo conocí modelo de pintores y que media Europa ha conocido en cueros - hermosos por evidencia-, y al famoso Milord del Nilo, Nelson, que deja el mar por seguir la Venus Parthenopea, de quien hace el amante spacimato». Carta de Azara a Bernardo de Iriarte de 3 de septiembre de 1800 citada por Gabriel SÁNCHEZ ESPINOSA, Memorias del ilustrado aragonés José Nicolás de Azara, Zaragoza, 2000, p. 243, n. 9. 


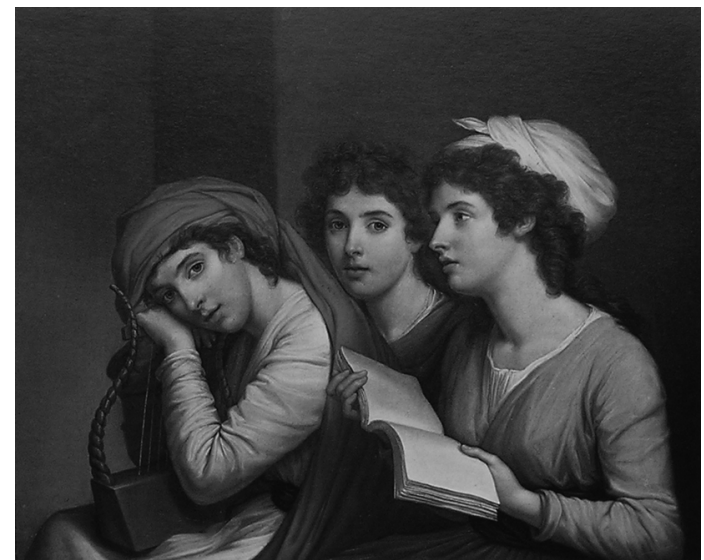

Fig. 1. Hugo Douglas Hamilton, Emma, lady Hamilton, en el papel de las tres Musas, c. 1789-1790. Escocia. Hamilton Collection.

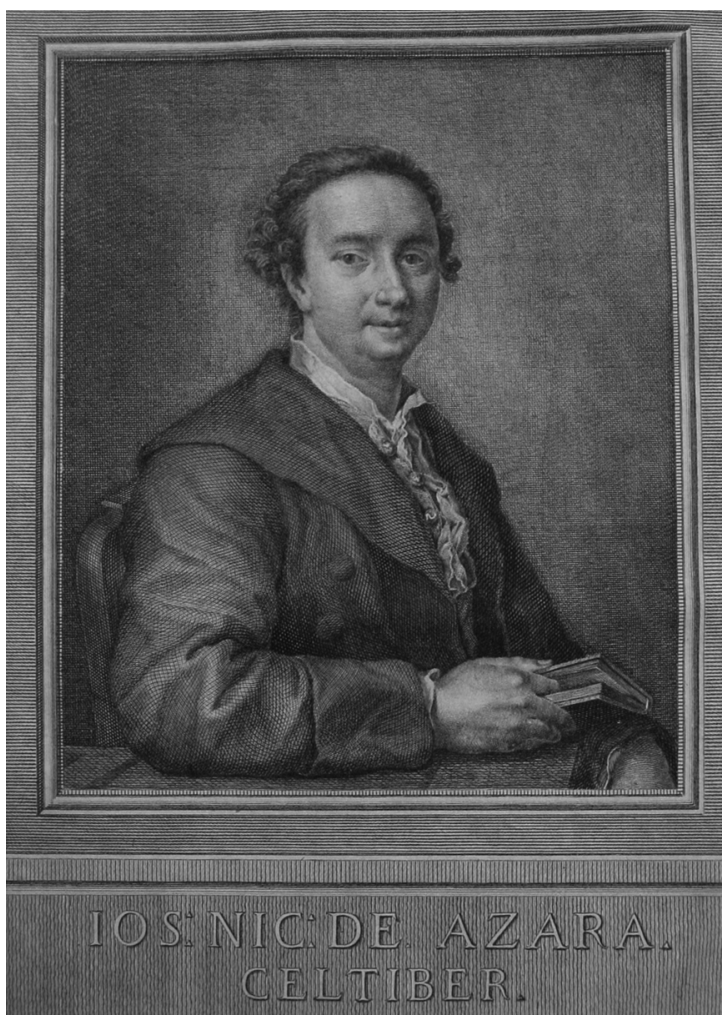

Fig. 2. Buenaventura Salesa (grabado de un retrato de Mengs), José Nicolás de Azara, en J. J. Winckelmann, Storia delle arti del disegno presso gli Antichi, II, 1783. 
Su figura ha sido ampliamente estudiada, por lo que aquí no nos detendremos en los múltiples aspectos políticos, científicos, literarios, arqueológicos y eruditos de los que se ocupó a lo largo de su vida, en vista de la ingente bibliografía acerca del tema. La dimensión multidisciplinar de sus inquietudes, su infinita cultura, su gusto por las antigüedades y por rodearse de los estetas y cultores del clasicismo, amén de los mecenas y artistas más renombrados de entonces, forjaron al hombre cultivado y cosmopolita que despertó la fascinación de los viajeros de paso por la Urbe; sin embargo, éste constituye uno de los aspectos del caballero Azara - que también compartió con Hamilton-menos atendidos por la investigación, tal vez por la dificultad que entraña dibujar el caso español dentro del fenómeno aristocrático del Grand Tour, en el que el aragonés se revela como un auténtico icono ${ }^{5}$.

\section{LA REALEZA VIAJERA}

A su modo, el marqués de Nibbiano representa con su propio devenir vital las inquietudes del viajero del Grand Tour, en un grado sublimado: el gusto por la Antigüedad no lo desplegó tan sólo en el coleccionismo de obras clásicas sino en la práctica de excavaciones arqueológicas; no se detuvo en la lectura de los autores grecorromanos, sino que además promovió la edición de nuevos estudios y traducciones (Virgilio, Prudencio, Horacio, Cicerón, Cátulo...) $)^{6}$. Su pasión viajera únicamente la pudo satisfacer en la medida que sus responsabilidades se lo permitieron. Rafael Olaechea y otros biógrafos de Azara citan los desplazamientos a Nápoles, Parma, Venecia, Florencia, Bolonia, Lucca, Milán, o Turín 7 , escapadas con móviles diplomáticos, de las que sin embargo extrajo el fruto de la investigación erudita: el besamanos de los reyes de Nápoles en 1765 le sirvió de excusa para encaminarse a Herculano e indagar entre sus ruinas guiado por dos lazzaroni, y cuando de nuevo descendió a Nápoles en 1788 redactó una serie de apuntes arqueológicos concernientes a las ciudades vesubianas. De paso por Florencia estudió la historia natural de las montañas toscanas, y los apuntes que tomó, donados en principio al Gabinete Científico de Roma, finalizaron en la imprenta en

5 Acerca de la escasa tradición española del Grand Tour, y de la reducida literatura española de viajes, Belén TEJERINA, «Las guías de viaje en el siglo XVIII y la nueva mentalidad de los viajeros», introducción a Leandro FERNÁNDEZ DE MORATÍN, Viage a Italia, Madrid, 1988, pp. 18-21; Maurizio FABBRI, «Literatura de viajes», en Historia Literaria de España en el siglo XVIII, Madrid, 1996, pp. 407-423; y Cesare DE SETA, L'Italia del Grand Tour de Montaigne a Goethe, Nápoles, 1996, p. 155.

6 Salvadora NICOLÁS GÓMEZ, «José Nicolás de Azara, representante en Italia del pensamiento ilustrado español», Academia, 54 (1982), pp. 253-256. Un ejemplo de la exhaustiva preparación de las publicaciones de Azara, tanto en el aparato ilustrativo, como en el contenido textual, aparece reflejado en Patrizia SERAFIN, «ll documento moneta nella Vida de Cicerón di José Nicolás de Azara», en IIluminismo e Ilustración. Le antichità e i loro protagonisti in Spagna e in Italia nel XVIII secolo, Roma, 2003, pp. 341-356.

7 Rafael OLAECHEA, «José Nicolás de Azara: literato y mecenas», en Actas del I Symposium del Seminario de Ilustración Aragonesa, Zaragoza, 1987, pp. 41-88 (la referencia en p. 45). 
17848. En Roma fue contemporáneamente atracción turística, sugestivo por el brillo que en él habían impreso las Letras y las Artes, y cicerone solícito - aunque no siempre entusiasta, y a menudo impelido por el compromiso institucional inherente a su cargo- de los visitantes en una ciudad que calificaba como la «más hermosa del mundo [...] y que todos los forasteros de Europa iban a ver como una maravilla por principio de buena educación»`. Sus primeros biógrafos ya destacaron esta faceta suya. Bourgoin apuntaba que «[...] En general, todos los extranjeros que llevaban a Roma la afición a las artes y que se le presentaban, eran recibidos con señales de distinción y benevolencia» ${ }^{10}$, y Castellanos de Losada recordaba cómo el papa Pío VI lo calificaba de «sábio ciceroni» de los soberanos que se daban cita en la Ciudad Eterna ${ }^{11}$. La primera visita regia a la que Azara atendió se desarrolló durante el prolongado y complicado cónclave que en 1769 elevó a Giovanni Vincenzo Ganganelli al trono de San Pedro bajo el nombre de Clemente XIV (pontífice entre 1769 y 1774). Relata Castellanos de Losada que entonces recaló en Roma el emperador del Sacro Imperio Romano José II (17411790), quien después de que su hermano Leopoldo José I, duque de Toscana (1747-1792) le presentara a Azara, no se separó ya de él durante su estancia romana (entre el 15 y el 30 de marzo), y que a menudo aseveraba que "daría la mitad de su imperio porque fuese súbdito suyo»'12. La estrecha cercanía del emperador y la agitación del cónclave mantuvieron alejado al cavaliere de sus afanes literarios, como se lamentaba a su amigo, oficial en la Secretaría de Estado, Eugenio Llaguno ${ }^{13}$; por el contrario, los dos monarcas ilustrados, satisfechos de este peregrinaje romano, a la par diplomático y cultural, quisieron dejar constancia de él en un retrato que refleja el lenguaje habitual del Grand Tour (con la Dea Roma a sus espaldas, el mapa de la ciudad desplegado en el escritorio, y en el fondo, el Castel Sant'Angelo y la basílica de San Pedro fundidos en una perspectiva inverosímil), recordado por Luigi Lanzi entre los retratos de mayor calidad creados por los pinceles de Pompeo Batoni ${ }^{14}$.

8 Basilio Sebastián CASTELLANOS DE LOSADA, Historia de la vida civil y política del célebre diplomático y distinguido literato español el magnífico D. José Nicolás de Azara, Marqués de Nibbiano, Madrid, 1849, vol. I, p. 162.

9 Gabriel SÁNCHEZ ESPINOSA, Memorias del ilustrado..., pp. 264 y 265.

10 M. BOURGOIN, Noticia histórica sobre el caballero D. José Nicolás de Azara, aragonés, embajador de España en París, muerto en dicha ciudad en 26 de enero de 1804, Madrid, 1846, pp. IX y X.

11 Basilio Sebastián CASTELLANOS DE LOSADA, Historia de la vida ..., vol. I, p. 194. Asimismo Sarrailh ha destacado el papel de cicerone desempeñado por Azara en Roma, Jean SARRAILH, La España Ilustrada de la segunda mitad del siglo XVIII, Madrid, 1979, pp. 372 y 373.

12 Basilio Sebastián CASTELLANOS DE LOSADA, Historia de la vida ..., p. 76.

13 «Este diantre de Imperatore con sus fiestas me ha sacado de mis casillas, sin dejarme tiempo para leer una ora», X. DE SALAS, "Cuatro cartas de Azara a Llaguno y una respuesta de éste», Revista de Ideas Estéticas, 13 (1946), p. 106.

14 Luigi LANZI, Storia pittorica della Italia dal Risorgimento delle Belle Arti fin presso al fine del XVIII secolo, Florencia, 1834 ( $5^{\mathrm{a}}$ ed.), tomo II, pp. 219 y 220. Acerca de esta obra, Anthony M. CLARK, "Neo-Classicism and the Roman Eighteenth-Century Portrait», Apollo, 78 (1963), p. 358 y fig. 4; AA.VV., Art in Rome in the Eigteenth century, Filadelfia, 2000, pp. 137 y 138, n. 172; y Renato MAMMUCARI, Settecento romano. Storia Muse Viaggiatori Artisti, Città di Castello (Perugia.), 2005, p. 174. 


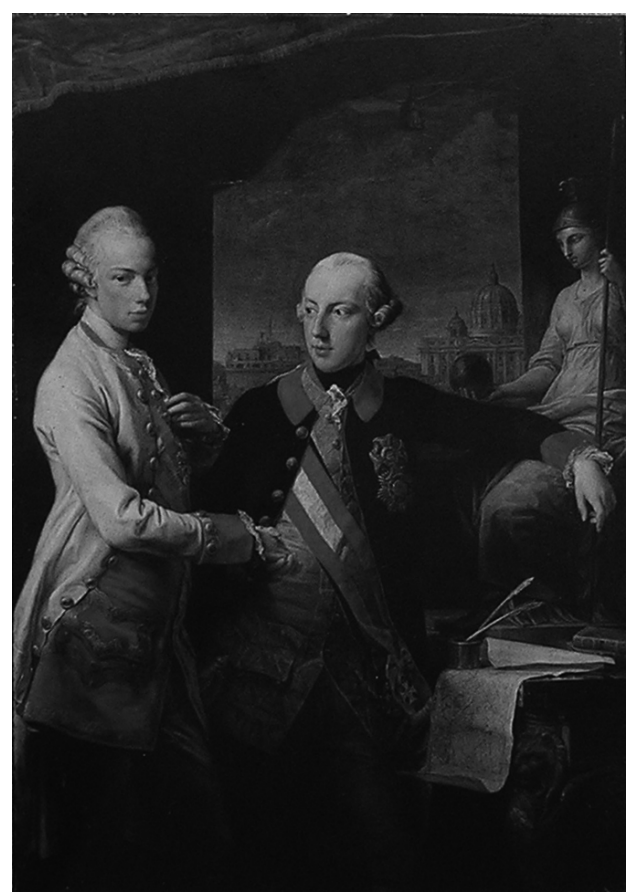

Fig. 3. Pompeo Batoni, El emperador del Sacro Imperio Romano José II y su hermano Leopoldo I, Gran Duque de Toscana, Kunsthistorisches Museum Collections

El 23 de diciembre de 1783 el emperador austriaco regresó a la ciudad del Tíber a fin de discutir con el pontífice las reformas que ideaba aplicar en el Imperio, en detrimento de los derechos de la Santa Sede, y preguntó en primer lugar por el paradero del caballero aragonés, quien a partir de su encuentro esa noche en el Teatro Alibert guió a aquél en sus paseos por la ciudad, y le aconsejó en materia política $^{15}$. Esto no dejó de crearle sinsabores, pues asimismo deseaba agasajar al rey Gustavo III de Suecia (1746-1793), que había viajado a Italia oculto bajo la identidad de conde de Haga, y se presentaba en Roma en idéntica fecha al anterior. Otro lienzo, ahora de Bénigne Gagnereaux, plasmó la sutil puesta en escena orquestada en torno al encuentro entre el pontífice Pío VI y el soberano de religión luterana, acaecido en el Museo Pío-Clementino, parada obligada en el periplo erudito por Europa ${ }^{16}$.

15 Carlos E. CORONA BARATECH, José Nicolás de Azara: un embajador español en Roma, Zaragoza, 1948, pp. 270 y 271.

${ }^{16}$ Christopher M. S. JHONS, «The Entrepôt of Europe», en Art in Rome..., pp. 17-45, p. 33; Andrew WILTON, e Ilaria BIGNAMINI, Grand Tour. Il fascino dell'Italia nel XVIII secolo, Milán, 1997, pp. 84-86 y n. 38 . 


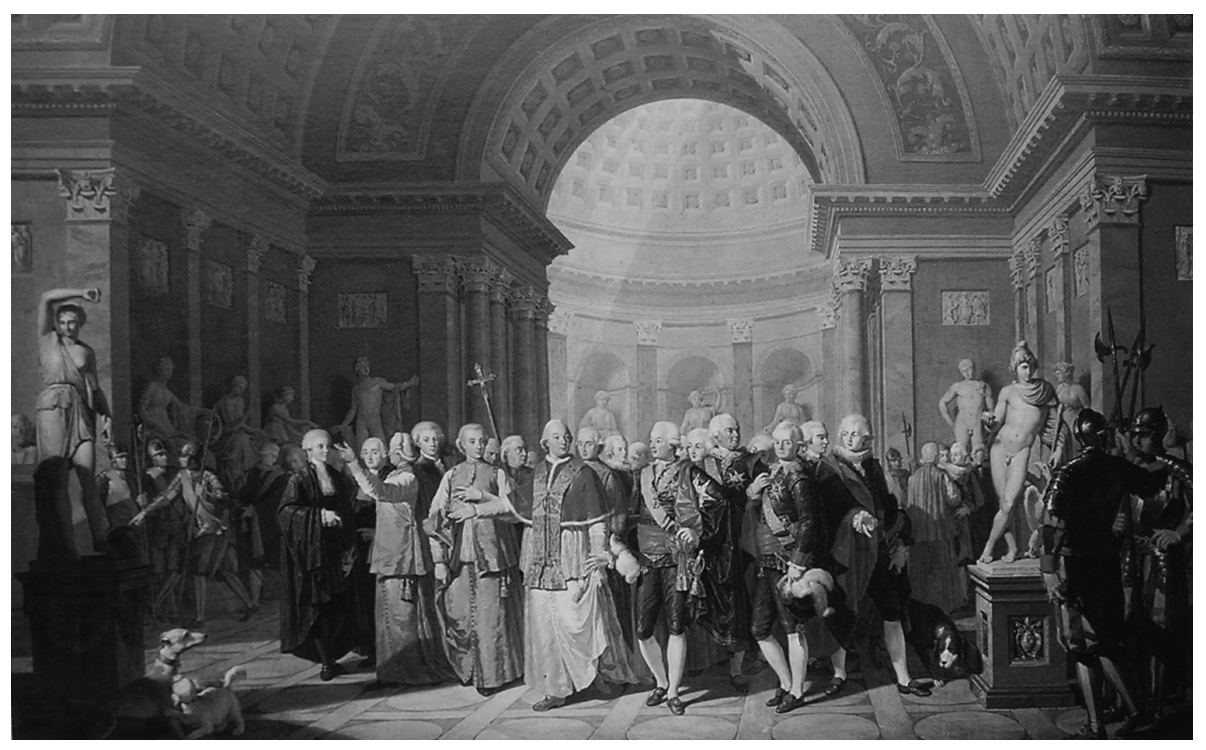

Fig. 4. Bénigne Gagnereaux, Pio VI acompaña a Gustavo III de Suecia durante su visita al Museo Pío-Clementino, 1786. Praga. Národni Galeri

Tras la partida de José II Azara se consagró a la persona del rey sueco —como él, coleccionista de antigüedades, y muy bien abastecido gracias a los servicios de su agente Francesco Piranesi- ${ }^{17}$, alternando sus atenciones con las reservadas a otra recién arribada, la archiduquesa de Austria María Amalia, compromisos y protocolos, teñidos de la afectación cortesana del Despotismo llustrado, a los que en esta ocasión se entregó gustoso ${ }^{18}$, y que después se perpetuaban en una nutrida correspondencia con las testas regias de todas las cortes europeas. La disponibilidad de Azara para con los eventuales viajeros promovió que el ministro plenipotenciario de turno - y asimismo el pontífice- delegara en su agente de Preces, y embajador di fatto, a la hora de obsequiar a los visitantes que atravesaban la Puerta del Popolo. Así, en 1768 Tomás Azpuru invitaba al conde de Aguilar a gozar de la filantropía de Azara, que renegaba del esfuerzo que le suponía dicha comisión ( Yo tengo que hacer de Cicerone y introductor de embajadores de dia y de noche, y Dios me asista, porque al tercer dia ya no puedo mas», le escribía al ministro Manuel de Roda), no tanto a causa de que el aristócrata español pretendiese contemplar todas las ruinas de Roma como por su carencia intelectual para apreciarlas ${ }^{19}$. Igualmente el marqués de Grimaldi dispuso que Azara acompañara en la capital

17 Rossana CAIRA LUMETTI, La cultura dei Lumi tra Italia e Svezia. II ruolo di Francesco Piranesi, Roma, 1990.

18 Basilio Sebastián CASTELLANOS DE LOSADA, Historia de la vida ..., p. 203 y ss.

19 El espíritu de Don José Nicolás de Azara descubierto en su correspondencia epistolar con Don Manuel de Roda, 3 vols., Madrid, 1846, vol. I, pp. 95 y 96. Cuando el conde de Aguilar partía hacia Venecia, Azara le escribía a Roda: «Si dura mas aquí, algunos amigos acabáramos de volvernos locos, habria para hacer un gran libro, con la materia que ha dado esta cosa de sí», Ibídem, vol. I, p. 98. 
pontificia a los archiduques de Milán, de quienes únicamente se separó en los tres meses (enero-abril de 1780) que permanecieron allí con el fin de embarcarse en una de sus empresas arqueológicas, las excavaciones en el templo de la Fortuna, en Neptuno ${ }^{20}$.

\section{JOSÉ NICOLÁS DE AZARA Y LOS VIAJEROS ESPAÑOLES}

La hospitalidad de Azara le franqueó la amistad de destacados personajes de la llustración española, pues todo viajero que se hubiera hecho un nombre en las Letras y las Ciencias, o con inquietudes artísticas, fue admitido en las elevadas tertulias del Palacio de España, la sede de la embajada. El acercamiento a sus privilegiados concurrentes constituía la llave de ingreso del viajero a las colecciones pontificias, a las bibliotecas señoriales, a las sociedades académicas y a las reuniones del patriciado romano ${ }^{21}$. A ellas asistían Ennio Quirino Visconti, el arquitecto Antonio Milizia, Mengs, el cardenal Zelada, o el grupo de antiguos jesuitas conectados al embajador mediante lazos de amistad y mecenazgo, como el mexicano Pedro José Márquez (1741-1820) o Esteban de Arteaga (1747-1799), tratadista por excelencia de la estética y la belleza ideal, y al igual que Azara gran amigo del impresor Bodoni. El padre Juan Andrés Morell, que narró epistolarmente a su hermano el itinerario italiano que realizó a lo largo de los años 1785, 1788 y 1791, resaltaba entre los compatriotas de mérito con los que se había topado fuera de España a José Nicolás de Azara, respetado en Roma, apuntaba, por su carácter, su talento, su saber y gusto ${ }^{22}$. Con toda seguridad el ministro aragonés lo ayudó a introducirse en los cenáculos humanistas a los que pertenecía y patrocinaba, y lo presentó a los artistas que acudían a las clases de dibujo que había instaurado en el Palacio de España, y que escoltaron al religioso en algunas de sus exploraciones de la Urbe ${ }^{23}$. Puesto que en 1785 Azara acababa de trasladarse a la legación, y sus colecciones y biblioteca se hallaban en fase de reorganización, Juan Andrés no tuvo la fortuna de pasearse por la galería de antigüedades de Azara, ni de examinar su nutrida pinacoteca, célebre en Roma por sus ricas pinturas de Mengs, Murillo o Velázquez ${ }^{24}$.

20 Basilio Sebastián CASTELLANOS DE LOSADA, Historia de la vida ..., pp. 173 y 174.

21 Salvadora NICOLÁS GÓMEZ, «José Nicolás ...», pp. 252 y 253.

22 Cartas familiares del abate D. Juan Andres a su hermano D. Carlos Andres, dandole noticia del viage que hizo a varias ciudades de Italia en el año 1791, publicadas por el mismo D. Carlos, Madrid, 1793, tomo I, pp. 12 y 13. En relación con el viaje a Italia del religioso español, Armando ALBEROLA ROMÁ, «Un viajero español de excepción por la Italia del siglo XVIII: el abate Juan Andrés Morell», Quaderni di filologia e lingue romanze. Ricerche svolte nell'Università di Macerata, Terza serie, 7 (1992), pp. 7-22.

${ }_{23}$ Podemos citar a los artistas José Camarón y Carlos Espinosa, en Cartas familiares..., tomo II, pp. 90 y 91. También, Javier Jordán de URRÍES DE LA COLINA, «Los últimos discípulos españoles de Mengs (Ramos, Agustín, Salesa, Napoli y Espinosa)», en I Congreso Internacional «Pintura Española siglo XVIIl’, Madrid, 1998, pp. 435-450, p. 447.

${ }_{24}$ Cartas familiares..., tomo I, pp. 12 y 13. 
Asimismo, la residencia de Azara siempre estuvo abierta a los jóvenes pensionados del rey o de la Academia de San Fernando que encontraban en las piezas de su colección modelos para copiar o imitar en sus propias creaciones, y a los viajeros que satisfacían su curiosidad turística en las demoras nobiliarias, a las que se accedía desembolsando propinas entre la servidumbre. Ponz recordaba su vasta biblioteca de autores clásicos, de medallas, de obras pictóricas de artífices como Mengs, Velázquez, Ribera o Murillo (Azara poseía tres cuadros de Murillo, uno de ellos adquirido al célebre castrato Farinelli), y las más de cuarenta cabezas de dioses, filósofos, capitanes, príncipes y poetas griegos acumuladas hasta el momento ${ }^{25}$. En 1780, Antonio Canova hojeó junto a Milizia una quincena de dibujos originales del recientemente difunto Mengs, y el retrato que el bohemio había ejecutado del cavaliere ${ }^{26}$.

Por otra parte, el eclesiástico y humanista oriundo de las Islas Canarias José Viera y Clavijo (1731-1813) ${ }^{27}$ también subrayaba la afición coleccionista del diplomático en una interesante descripción de su domicilio junto al Palacio de Monte Cavallo ${ }^{28}$. El autor de la Historia de las Islas Canarias se embarcó durante 1780 y 1781 en un largo viaje de Grand Tour en el que recorrió las ciudades de Italia y Alemania en compañía del marqués de Santa Cruz y del hermano de éste, el presbítero Pedro de Silva. Clavijo estimaba a Azara «uno de los españoles que hacen mas honor á la nacion por su espíritu, su ilustracion, su talento y gran política ${ }^{29}$, lo cual se demostró durante el tiempo que permanecieron en Roma. El agente de Preces los introdujo en el círculo de visitantes asiduos de la embajada (la princesa de Santacroce, el embajador de Malta, el cardenal de Bernis, el cardenal Zelada; también contactaron con el grupo de exjesuitas residentes en la Urbe: el abate Calderini, el abate Huerta, etc.), los animó a participar en sus tertulias, y se sentaron

25 Sobre la colección de Azara consúltese Miguel Ángel ELVIRA BARBA, «Las antigüedades romanas en el Jardín del Príncipe y la Casa del Labrador», Reales Sitios, XXXI (1994), pp. 57-65; Beatrice CACCIOTTI, «La collezione di José Nicolás de Azara: studi preliminari», Bollettino d’Arte, 78 (1993), pp. $1-54$.

26 Elena BASSI, Antonio Canova. I quaderni di viaggio (1779-1780), Florencia, 1959, p. 137.

27 Acerca de este erudito, miembro de la Academia de la Historia, y arcediano de Fuerteventura, ver Enrique ROMEU PALAZUELOS, Biografía de Viera y Clavijo a través de sus obras, Santa Cruz de Tenerife, 1981; Victoria GALVÁN GONZÁLEZ, La obra literaria de José de Viera y Clavijo, Las Palmas de Gran Canaria, 1999; y José de VIERA Y CLAVIJO [Del Epistolario de], El arcediano que tenía la sonrisa de Voltaire, Editorial Leoncio Rodríguez/Editora de Temas Canarios, El Masnou, 2001.

28 «La casa del referido Azara no es muy grande, pero tiene un lindo jardin, si bien lo mas curioso de ella, son los estudios, bosquejos y algunas otras pinturas del célebre Antonio Rafael Mengs, cuyos escritos sobre la pintura ha ordenado y publicado en español y en italiano, el mismo caballero Azara su fiel amigo. Entonces tenía todavia en su casa el cuadro hermoso de la Anunciación que por su muerte no habia podido concluir Mengs, y que destinaba para el rey N. S. como con efecto se remitió luego a Madrid. Así mismo tenía el señor Azara en su gabinete algunas cabezas antiguas en mármol de diversos filósofos; halladas últimamente en unas excavaciones hechas no sé en qué paraje de Roma por su cuenta; como también las copias de unas pinturas al fresco igualmente descubiertas poco antes», en José VIERA Y CLAVIJO, Estracto de los apuntes del diario de mi viaje desde Madrid a Italia y Alemania en compañía del Exmo. Sr. D. José de Silva Bazán, Marqués de Santa Cruz... y de su hermano el Sr. D. Pedro de Silva Presbítero Comendador de Eljas en la órden de Álcántara, Capellan mayor del Convento Real de la Encarnación, por los años de 1780 y 1781, Santa Cruz de Tenerife, 1849, p. 66.

29 Ibidem, p. 59. 
habitualmente en su mesa. Junto a Azara exploraron muchas de las maravillas que ofrecía Roma y sus alrededores a los forasteros. A principios de julio de 1780 pasaron unos días con el diplomático en Albano, hospedados en el palacio del cardenal de Bernis, obispo de aquella ciudad, excursión a la que se unieron el embajador de Malta y los príncipes de Santacroce ${ }^{30}$. En sus salidas por la campiña de los Colli Albani pasearon a lo largo de la Vía Appia, admiraron el Sepulcro de los Horacios y los Curacios, los palacios del príncipe Chigi y de la princesa Barberini en Palestrina, y en la propia localidad lacial, el Palacio Corsini, la catedral y las termas romanas. De vuelta a la ciudad del Tíber los viajeros transcurrieron una buena parte de su tiempo en los talleres de los artistas locales y extranjeros: Pompeo Batoni les mostró los lienzos que ejecutaba en aquel momento, e incluso una noche les invitó a que escucharan el coro formado por sus numerosas hijas; en el estudio de los hijos de Piranesi contemplaron su copiosa colección de estampas, amén de estatuas, bajorrelieves, vasos y candelabros, y también examinaron la obra pictórica de artistas de nacionalidad alemana, inglesa y danesa.

Y, por supuesto, no olvidaron verificar la visita obligada a sus compatriotas, los pensionados españoles que se educaban en las distintas especialidades de las Nobles Artes: «Estuvimos en casa de don Francisco Preciado, pintor del Rey, director de los pensionados de la academia de San Fernando de Madrid en Roma, cuya muger maneja tambien el pincel con gran primor. Asimismo estuvimos en la posada de los jóvenes españoles, pensionados por la dicha Academia para instruirse en pintura, escultura y arquitectura, y vimos sus estudios en las mismas artes» ${ }^{31}$. La deferencia de Azara hacia Clavijo y sus compañeros a lo largo de ese mes prosiguió hasta el día previo a su partida de Roma, con dirección a Nápoles, cuando los llevó hasta el Palacio del Quirinal a fin de que se despidieran del Santo Padre.

Además del marqués de Santa Cruz, otros viajeros de la aristocracia española, o sus vástagos en viaje de estudios, se acogieron en la capital pontificia a la hospitalidad de Azara, y se beneficiaron de su prodigalidad a la hora de ilustrar a sus huéspedes sobre las antigüedades de la ciudad, o a presentarlos en la sociedad romana, labores que aquél entendía como un deber, cuyo cumplimiento estimularía a sus compatriotas a continuar saliendo más allá de nuestras fronteras; porque dentro de ellas, el diplomático, siguiendo el flujo del pensamiento en boga en el Siglo de las Luces español, apenas veía algo más que una nación políticamente estancada, y una masa sometida al clero, la barbarie y la superstición, gobernada por unas mentes malogradas a causa de la rancia instrucción universitaria $^{32}$. Por eso su intención adoctrinadora se halla muy presente en esta altruista función de cicerone asumida voluntariamente.

30 Ibidem, p. 104 y ss.

31 Ibidem, p. 117.

32 Rafael OLAECHEA, «José Nicolás ...», pp. 44 y 45. Por ejemplo, en 1769 escribía Azara a Manuel de Roda que el hijo del consejero Mata, colegial de San Bartolomé, estaba en Roma después de haber viajado por Inglaterra y Francia; el aragonés se lamentaba de su apego a la «grasa colegial» y se proponía ponerlo en el buen camino. El espíritu..., vol. I, pp. 252 y 253. 
El conde de Fuentes - embajador en París y futuro afrancesado - el duque de Arcos, el marqués de Llano o el conde de Carlet también frecuentaron al diplomático, en tanto que el resto de sus compromisos se lo permitieron ${ }^{33}$. Los palcos de los teatros, las mesas de la nobleza romana, las galerías de arte, y la ciudad, la antigua y la barroca, se distinguieron como los escenarios donde se desenvolvieron los actos sociales en los que les resplandeció el marqués de Nibbiano. Por encima de todo deseó inculcar su pasión por las monumentales ruinas de la civilización clásica a los españoles a los que daba la bienvenida; en 1773, "don Luisito» (Luis Pignatelli), hijo del conde de Fuentes, se detuvo en la Urbe de camino a Nápoles y contempló sus antigüedades junto a Azara, así como su padre haría pocos años más tarde: «Yo me estoy aquí plantado como una col, y acompaño á ver l'antichità al conde de Fuentes, que viene de Sicilia, y está alojado en mi casa» ${ }^{34}$. No siempre encontró placer en la tarea que se impuso de educar a los hijos de la nobleza embarcados en su Grand Tour, a causa de la divergencia entre sus intereses, de los entretenimientos que requerían, o de su manifiesta indolencia hacia el estudio. Del sobrino del ministro de Hacienda Miguel Múzquiz indicaba en tono írónico a Manuel de Roda "saldrá de aquí sabiendo menos de Roma que yo de Constantinopla» ${ }^{35}$; tampoco el joven Orcasitas necesitaba una atención particular del cicerone aragonés, que describía sus inclinaciones en pocas palabras: «baila que se las pela, y ve mucho moderno y poco antiguo ${ }^{36}$. José Moñino, conde de Floridablanca, le encomendó el cuidado de su sobrino y de su mentor, comisión que Azara no aceptó de muy buen talante: «Ahora toca a mí llevarlos a cuestas y hacerles de cicerone, que me sirve de un gustillo cual usted se puede figurar ${ }^{37}$. Pero sin embargo todos demandaban la cercanía de Azara, pues como le recomendaba en 1770 el conde de Peñaflorida a su segundo hijo, Ramón Munibe, «en qualquiera parte a que llegues te has de introducir primero con los savios mas conocidos, y despues con las personas mas respetables por su nacimiento y caracter ${ }^{38}$. $\mathrm{Y}$ ambas condiciones confluían en el marqués de Nibbiano.

\section{RELACIONES ENTRE AZARA Y LOS «CURIOSOS IMPERTINENTES» EN MADRID Y ROMA}

Entre 1774 y 1776 que el cavaliere permaneció con licencia de Carlos III en España hizo gala de esa hospitalidad hacia los extranjeros que desplegaría sobre todo a su regreso a Roma, e invitado al Real Sitio de la Granja por Carlos III de Borbón, no dudaba en guiar a los forasteros por sus jardines para que admiraran

${ }^{33}$ Véase Jean SARRAILH, La España ..., p. 372.

${ }^{34}$ El espíritu..., vol. III, p. 198.

35 Ibidem, vol. I., p. 183.

36 Ibidem, vol. I, p. 288.

37 Ibidem, vol. III, p. 59.

${ }_{38} \mathrm{~J}$. DE URQUIJO, Los Amigos del País (según cartas y otros documentos inéditos del XVIII), I, San Sebastián, 1929, p. 53. 
los juegos de agua de sus fuentes, y equiparaba su belleza a la de las villas de Tívoli, Albano o Caserta ${ }^{39}$.

En Madrid, en torno a estas fechas entró en contacto con dos personalidades de origen británico sobre las que se formaría una opinión bien diversa. El literato Henry Swinburne (1743-1803), a quien Azara criticó con encono por su frivolidad con la pluma al describir el pueblo y las costumbres españolas en una de sus obras ${ }^{40}$, cuando en nuestro país, que recorrió entre 1775 y 1776 junto a Thomas Gascoigne, había sido objeto de múltiples atenciones, y también en su viaje a Italia (1777-1779): «Por espacio de dos años (escribía Azara) he visto la distinción y los favores que ha debido a los españoles que estamos aquí, disfrutando los más días de la casa y mesa de nuestro embajador ${ }^{41}$. En el prólogo de la traducción castellana hecha por el hidalgo aragonés de la Introducción a la historia natural y a la geografía física de España (Madrid, 1782) del naturalista irlandés William Bowles ${ }^{42}$, presentaba un relato de Swinburne sobre una España «estúpida hasta el letargo, pobre, puerca, celosa y melancólica» cargado de tópicos (el mal estado de caminos y posadas, las citas recurrentes de El Quijote y Gil Blas, la impiedad y estupidez de los habitantes), en el que se exaltaba el pasado andalusí para desprestigiar el país:

«Aunque su erudición singular pudiera explayarse describiendo las muchas antigüedades romanas que se conservan en esa península, merced a los siete siglos de la culta, suave y humana dominación moruna, apenas hace mención de nada de esto en su libro, como ni tampoco de nuestras academias, bibliotecas, gabinetes de antigüedades y de Historia Natural, Jardín Botánico, bellas artes, comercio, manufacturas, caminos magníficos que se han hecho y continúan, porque sin duda creyó que tales frioleras no podrían mover la curiosidad de sus compatriotas, mayormente cuando ya se lo dice todo, asegurándoles que los literatos de España no pasan de media docena»43.

La defensa de España, o cuanto menos de sus posibilidades de desarrollo, que desde Jovellanos o Ponz hasta José Ortiz y Sanz (valedor del patrimonio artístico y monumental del país frente a las voces de los viajeros extranjeros, "viandantes sin ciencia ni prudencia») $)^{44}$, había constituido un rasgo definitorio de nuestra eru-

39 Basilio Sebastián CASTELLANOS DE LOSADA, Historia de la vida ..., vol. I, p. 115.

40 Henry SWINBURNE, Travels through Spain, in the years 1775 and 1776, Londres, 1779. En 1787 se reeditó su libro, año en el que además La Borde publicó una traducción al francés. Acerca de Swinburne, cfr. Ana Clara GUERRERO, Viajeros británicos en la España del siglo XVIII, Madrid, 1990, p. 65 y ss.

41 Ver Antonio PONZ, Viaje de España: seguido de los dos tomos del Viaje fuera de España, Madrid, 1947 , vol. I, pp. 1667 y 1668.

${ }_{42} \mathrm{Al}$ año siguiente Milizia tradujo la obra al italiano, que se publicó con el títutlo Introduzione alla storia naturale e alla geografia fisica di Spagna di G. Bowles. Pubblicata e comentata dal Cav. D. Giuseppe Niccola D'Azara e dopo la seconda edizione spagnola più arrichita di note, Parma, 1783.

43 Antonio PONZ, Viaje de España ..., vol. I, p. 1668. El poco gusto de los españoles por las letras lo señalan a menudo los viajeros extranjeros, desde Casanova, como remarca Ricardo BAEZA, "Casanova en España. Conclusión», Revista de Occidente, tomo IV, X (1924), p. 88, a Townsend o el marqués de Langle.

44 Noticia y plan de un viaje Arquitectónico-Antiquario, encargado por S.M. a Don Joseph Francisco Ortiz el año de 1790, Madrid, 1797, p. 10. 
dición dieciochesca ${ }^{45}$, se manifestaba en las palabras de Azara, quien con semejante ánimo se arrogaba la prerrogativa ilustrada de ventear las miserias de su nación, como a menudo se lee en su correspondencia, sin permitir que los extranjeros, inexpertos en estos asuntos ajenos, lo imitaran. Por ello, tuvo mayor aceptación - a tenor de las connotaciones favorables hacia España-Travels through Spain (Londres, 1780) de John Talbot Dillon, una revisión en lengua inglesa, ahora reestructurada en estilo epistolar, de la publicación de Bowles ${ }^{46}$, que su autor dedicó al barón Grantham (1738-1786).

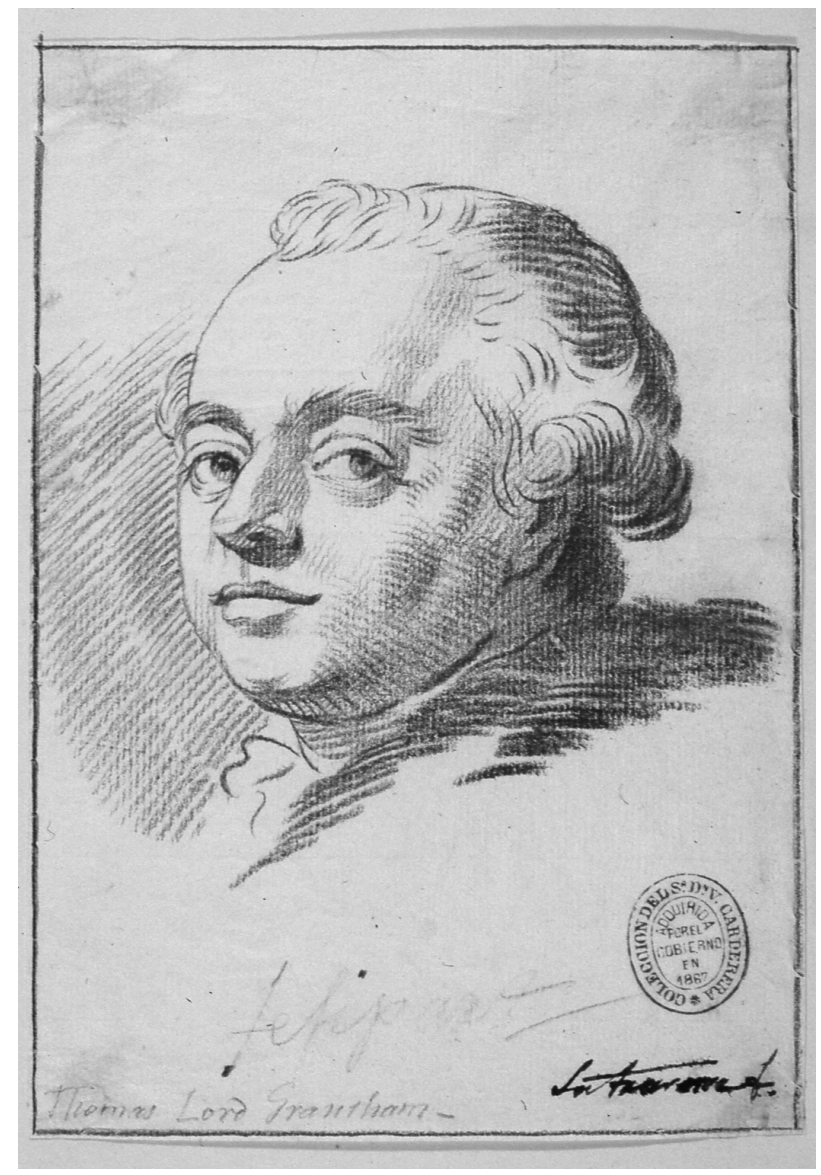

Fig. 5.Carlos de la Traverse, Lord Grantham, último tercio del s. XVIII. Madrid. BN, B-9180

45 Consúltese Alicia LEÓN GRANDE, Imágenes arqueológicas de la España ilustrada. El teatro romano de Sagunto en el siglo XVIII, Sevilla, 2006, pp. 35-42.

46 La obra fue traducida al castellano dos años después. John Talbot DILLON, Nuevo viaje en España, hecho en 1777 y 1778, en que se trata de las costumbres, carácter, monumentos antiguos y modernos, comercio, teatro, legislación, tribunales, etc., Madrid, 1782. 
Durante los dos años que Azara permaneció fuera de Italia entabló una íntima amistad con Thomas Robinson -lord Grantham-, embajador de Inglaterra destacado en Madrid de agosto de 1771 a julio de 1779, cuando se rompieron las relaciones diplomáticas con aquel país ${ }^{47}$. Ambos hacían carrera en la política exterior y compartían el gusto por las Bellas Artes, prenda que subrayaba Ponz en el lord inglés ${ }^{48}$. En Madrid se relacionó con artistas de la talla de Juan de Villanueva, que le enseñó sus dibujos arquitectónicos, y le obsequió con uno de la parte frontal del monasterio de El Escorial, del que el embajador reseñaba algunos defectos relativos a su utilización de la cámara oscura en una carta remitida a su hermano, Frederick Robinson (1746-1792) ${ }^{49}$. Otro genial artista español que aparece citado en la documentación junto al embajador de Inglaterra es Francisco de Goya, de cuyo talento tenía aquél referencias a través del propio Carlos III, dado que en sus pasos iniciales en la Corte el artista reproducía diferentes telas de las colecciones reales para la elaboración de una serie de grabados. Antonio Ponz, por entonces secretario de la Real Academia de San Fernando, mostró a lord Grantham las copias del pintor de Fuendetodos de "some beggarly Philosopher», el fabulista Esopo y el filósofo cínico Minipo que Diego de Silva y Velázquez encarnó en grotescos pordioseros ${ }^{50}$. Fascinado por la precisión pictórica de Goya, el diplomático británico le habría encargado la reproducción de otra obra de Velázquez, el presunto autorretrato que se expone en el Museo del Prado ${ }^{51}$.

Estando Azara desempeñando su cargo de agente Preces en la ciudad del Tíber, Grantham mantuvo correspondencia con él y con Mengs, quien en el verano de 1777 pintaba un lienzo por encargo del embajador inglés ${ }^{52}$. Esta comisión la había recibido el bohemio a principios de los años 60, cuando comenzó a retratar a Grantham simultáneamente que el pintor americano Benjamin West (1738-1820), cuyos bocetos, confundidos con los de aquél en una mascarada arreglada para

\footnotetext{
47 Ian ROBERTSON, Los curiosos impertinentes, viajeros ingleses por España desde la accesión de Carlos III hasta 1855, Barcelona y Madrid, 1988, p. 316.

48 «Todos han conocido en Madrid a dicho caballero, último embajador de su majestad británica; todos tienen noticia de su instrucción en las ciencias y bellas artes, y cuantos lo trataron pueden decir de sus amables prendas y demás circunstancias, que le hicieron digno de la mayor estima en la corte». Antonio PONZ, Viaje de España ..., p. 1671.

49 Bedfordshire and Luton Archives (desde ahora BLA), Manuscripts, L 30/15/54/30. Carta de Thomas Robinson a Frederick Robinson de 20 de abril de 1778.

50 BLA, Manuscripts, L 30/15/54/48. Carta de Thomas Robinson a Frederick Robinson de 18 de junio de 1778. Sobre ambos filósofos, Yves BOTTINEAU, Vélazquez, París, 1998, p. 195 y figs. 156-157. Un dibujo preparatorio de Esopo se conserva en la Fundación Lázaro Galdiano ( $n^{\circ}$ de inventario 10624), junto a varios grabados de ambos personajes; también un grabado de «Moenippus» pertenece al Consejo Social de la U.C.M. (invent. C.U.C. 1156), «Sacada y gravada del Quadro original de D. Diego Velazquez que existe en el RI. Palacio de Madrid, por D. Fran.co Goya Pintor, año de 1778. Representa à Menipo Filosofo de la estatura natural». Ver Elena MUÑOZ CARPINTERO y Ma Julia IRIGOYEN DE LA RASILLA, Patrimonio artístico de la facultad de Bellas Artes. Inventario, Madrid, 2002, p. 19. Sendas copias al óleo de Esopo y Menipo se localizan en la Real Sociedad Económica Aragonesa de Amigos del País, con toda probabilidad las que Goya mostró a lord Grantham en 1778.

51 Museo del Prado. Inventario general de pinturas. I. La colección real, Madrid, 1990, n 139.

52 Steffi ROETTGEN, Anton Raphael Mengs 1728-1779. Band I. Das malerische und zeichnerische werk, Munich, 1999, pp. 295 y 296, n²28.
} 


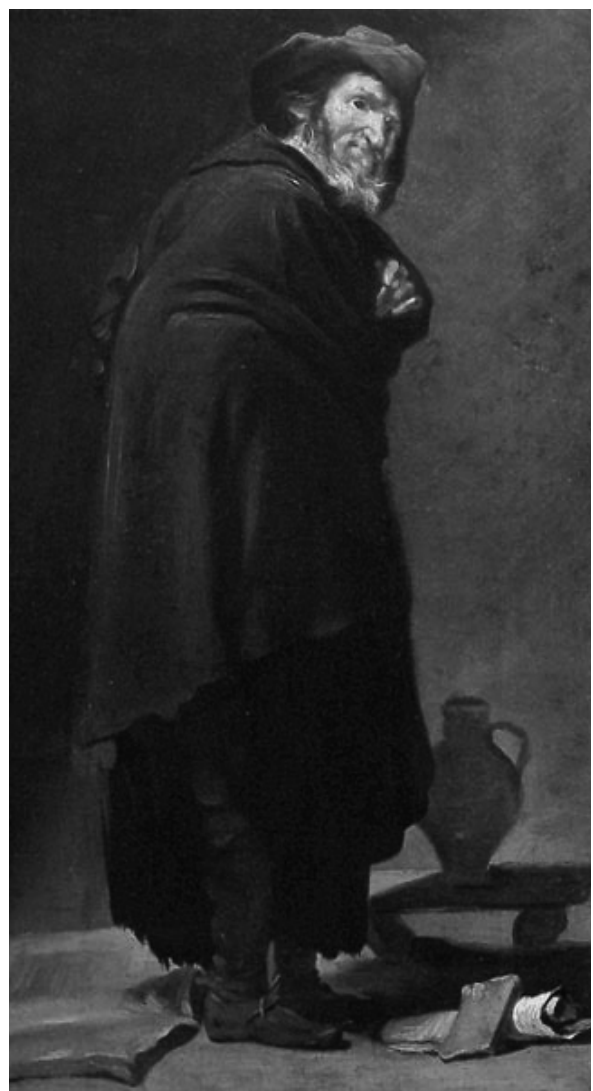

Fig. 6. Francisco de Goya, Menipo, 1778. Real Sociedad Económica Aragonesa de Amigos del País

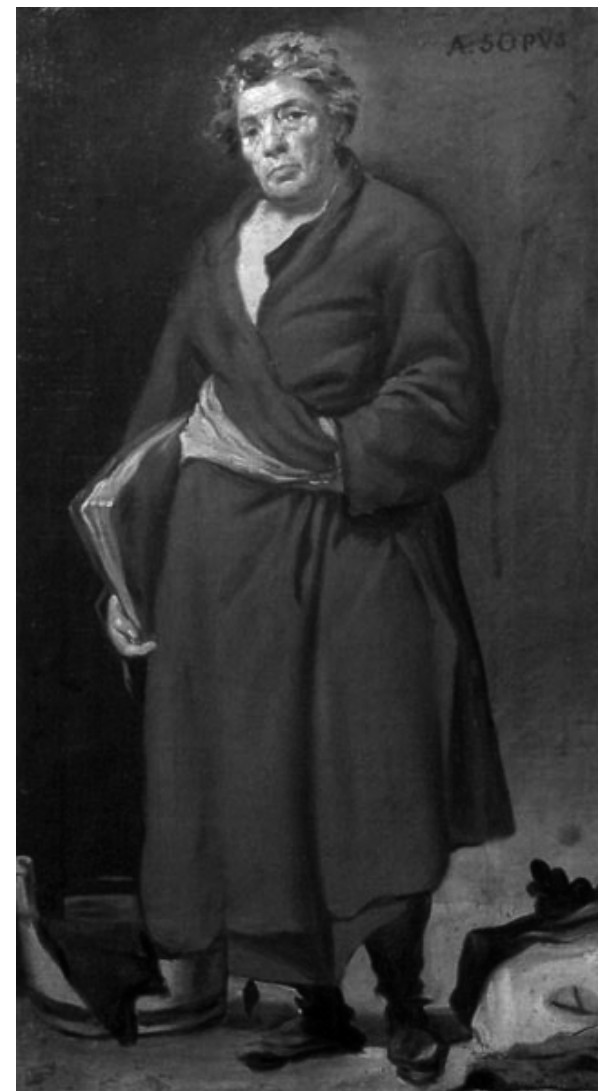

Fig. 7. Francisco de Goya, Esopo, 1778. Real Sociedad Económica Aragonesa de Amigos del País

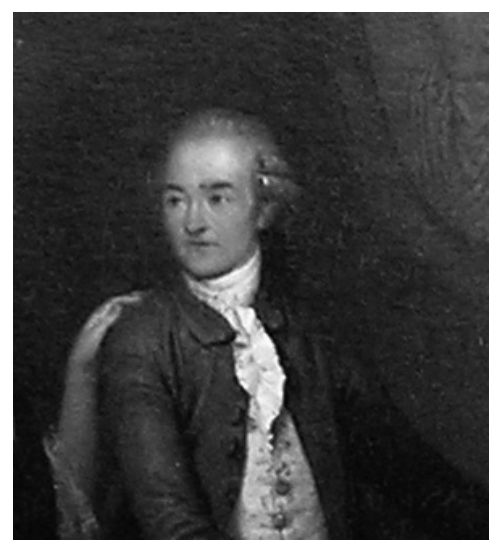

Fig. 8. Franciszek Smuglewick, James Byres de Tonley con su familia (detalle), c. $1775-1778$, Scottish Nacional Portrait Gallery 
azorar a otros artistas y amateurs, se habían juzgado los más coloridos que hubieran salido jamás de la mano de Mengs.

En junio de 1778 Grantham se dirigía a éste, al ministro aragonés y a James Byres (1733-1817) para solicitar que una serie de piezas - de las que no se aportaba mayor información, si bien estaría incluida la obra del artista alemán- le fueran expedidas con la mayor premura ${ }^{53}$. En ésta y otra carta los nombres de Azara, Mengs y Byres aparecen vinculados. Byres, al que se definió como el "papa de los anticuarios de Roma», era un pintor-arquitecto con aficiones arqueológicas, miembro de la Sociedad de Anticuarios de Londres y de la Real Sociedad de Edimburgo, que a lo largo de los cuarenta años que habitó en Italia reunió una importante colección de esculturas antiguas. En cada localidad italiana a donde se desplazaba el turismo europeo determinados artistas y anticuarios controlaban como auténticos comerciantes el mercado del souvenir -láminas, antigüedades, libros, etc. - que el viajero atesoraba como recuerdo. En el tercio final de siglo, el panorama turístico inglés que acudía a la capital pontificia contaba con la referencia imprescindible de dos personajes, Thomas Jenkins y en menor medida James Byres, quienes dictaron el gusto del coleccionismo de los visitantes del Grand Tour durante décadas ${ }^{54}$.

Byres pertenecía al grupo de dealers escoceses asentados en Roma, que adoptando como epicentro la Plaza de España, se aplicaban en impartir intensivos cursos de arquitectura y anticuariado entre sus adinerados compatriotas que se prolongaban a lo largo de seis o más semanas; ni que decir tiene que el maestro en cuyo taller se formó Byres en su juventud, el propio Mengs, resultó muy beneficiado económicamente de la red de contactos madurada por su pupilo, y recibió distintos encargos de coleccionistas extranjeros ${ }^{55}$. Gavin Hamilton y Colin Morison, directo competidor de Byres, y como él, alumno de Mengs, completan la triada más notoria de estos artistas escoceses dotados de una aguda vista para los nego$\operatorname{cios}^{56}$. Byres cumplió además con las funciones de agente de Thomas Robinson en la Urbe, y posiblemente Azara interviniera también en estas operaciones, en razón de los intereses comunes y la amistad que lo ligaba a aquél, por lo que cuando Mengs informó a Grantham que su cuadro se hallaba finalizado, pero que todavía seguiría retocándolo, el inglés le dirigía una misiva a Byres para que se lo quitase ya de las manos ${ }^{57}$; en términos similares se había expresado en su carteo con Aza-

53 BLA, Manuscripts, L 30/15/54/48. Carta de Thomas Robinson a Frederick Robinson de 16 de junio de 1778 .

54 Brian ALLEN, «Artistas y viajeros británicos en Italia al final de la década de 1770», en José M LUZÓN NOGUÉ (ed.), El Westmorland. Recuerdos del Grand Tour, Madrid, 2002, pp. 23-37 (la referencia en pp. 30 y 31$)$.

55 Steffi ROETTGEN, Anton Raphael Mengs (1728-1779) and his British Patrons, Londres, 1993, p. 16.

56 Jonathan SCOTT, The pleasures of Antiquity. British Collectors of Greece and Rome, Yale, 2003, pp. 101 y 102.

57 BLA, Manuscripts, L 30/15/54/69. Carta de Thomas Robinson a Frederick Robinson de 20 de agosto de 1778. En el Archivio di Stato di Roma hemos localizado numerosas expediciones de antigüedades y obras de arte a sus clientes extranjeros por parte de James Byres y su sobrino, amén de colaborador, 
ra el marqués de Llano, embajador en la Corte de Parma, a propósito de la indolencia con que entre 1771 y 1772 Mengs ejecutaba el retrato de su esposa, Isabel Parreño Arce, el cual fue copiado por diferentes artistas ingleses antes de llegar a poder de su enojado comprador ${ }^{58}$. Durante sus años en la embajada Azara debió de mantenerse en estrecho contacto con personajes bien acomodados en el mercado del anticuariado romano como Byres y Jenkins, y con los talleres de escultura que restauraban - y reinventaban - los mármoles, hasta el punto de compadecerse de los anticuarios y artistas que a falta de su clientela de forasteros «morían de hambre" en el periodo de las guerras con Francia ${ }^{59}$. Estos contactos le habrían resultado de gran utilidad de haber proseguido con el plan de regresar a Roma a vender su colección pictórica y de escultura antigua a los marchantes ingleses cuando a comienzo del siglo XIX, destinado en París, Carlos IV desatendía a sus ruegos de costear su transporte hasta España ${ }^{60}$.

También de la colonia británica en Madrid, en su permiso sabático en España Azara pudo entrar en relaciones con Thomas Pelham -lord Chichester- (17561826), cuya familia mantenía lazos de amistad con lord Grantham, y que en 1775 se encontraba allí con el objetivo de aprender el castellano. Después de su Grand Tour por Francia, Alemania y Austria, lord Chichester visitó Italia antes de retornar en 1778 a su país, y en Roma se mantuvo en estrecha conexión con Azara, quien lo invitaba a su mesa a menudo ${ }^{61}$. En julio de 1777 se acercó a las excavaciones que el aragonés efectuaba en la villa Negroni Montalto -donde por aquel entonces habitaba-, como el mismo aristócrata inglés afirmaba en su correspondencia con Frederick Robinson: «he is concerned in an excavation at the Villa Negroni wich $i$ believe will turn out very well, ${ }^{62}$. Pelham no se engañaba, ya que ese verano una multitud de curiosos escrutó la cava de Azara con objeto de admirar las pinturas murales descubiertas en lo que hoy sabemos que fue una domus urbana de época adrianea ${ }^{63}$. A medida que se fueron desenterrando las cinco salas cuyas pare-

Patrick Moir. Consúltese ASR. Camerale II. Antichità e Belle Arti. Busta 13, o Busta 14, fascs. 298-300. Asimismo, Brinsley FORD, «James Byres. Principal Antiquarian for the English Visitors to Rome», Apollo, XCIX, 148 (1974), pp. 446-461.

58 José VALVERDE MADRID, «El retrato de la marquesa de Llano, por Mengs», Goya, 210 (1989), pp. 327-329; Steffi, ROETTGEN, Mengs. La scoperta del Neoclassico, Venecia, 2001, pp. 306-308 y n. 108.

59 Juan de CONTRERAS Y LOPEZ DE AYALA, MARQUÉS DE LOZOYA, «Cartas dirigidas por D. José Nicolás de Azara al pintor de Cámara D. Francisco Javier Ramos», Academia, 8 (1959), pp. 13-27 (especialmente pp. 24, 25 y 27).

60 Javier Jordán de URRÍES DE LA COLINA, «Azara, coleccionista de antigüedades, y la Galería de estatuas de la Real Casa del Labrador en Aranjuez, Reales Sitios, 156 (2003), pp. 57-70, p. 61. Hasta 1804 no llegó a nuestro país la colección de Azara, hoy dispersa entre el Real Sitio de Aranjuez y el Museo del Prado.

61 "I dined with Azara the other day whose friendship to me is as constant as ever; indeed his acquaintance is most valuable and $i$ shall miss dining with him on Tuesday, Thursday and Sundays as few times as i can". BLA, Manuscripts, L 30/15/42/12. Carta de Thomas Pelham a Frederick Robinson de 10 de julio de 1777. 1777.

${ }_{62}$ BLA, Manuscripts, L 30/15/42/12. Carta de Frederick Robinson a Thomas Pelham de 10 de julio de

${ }^{63}$ Sobre su datación, R. PARIS y otros, Antiche stanze. Un quartiere di Roma Imperiale nella zona di Termini, Roma, 1996, p. 31. 
des estaban adornadas, se serraron los cuadros con las imágenes mitológicas figuradas y se extrajeron los paneles para ser entregados por 50 coronas al pintor Henry Tresham, el «certo Negoziante Inglese» al que aludía como comprador el diario romano Chracas $^{64}$, que seguidamente se las vendió al Obispo de Derry, $4^{\text {th }}$ Earl of Bristol (1730-1803). En sus visitas a la villa Negroni Tresham llevó consigo al también pintor Thomas Jones, autor de un óleo sobre los trabajos arqueológicos de Azara, y cuya descripción encontramos en su diario de viaje ${ }^{65}$.

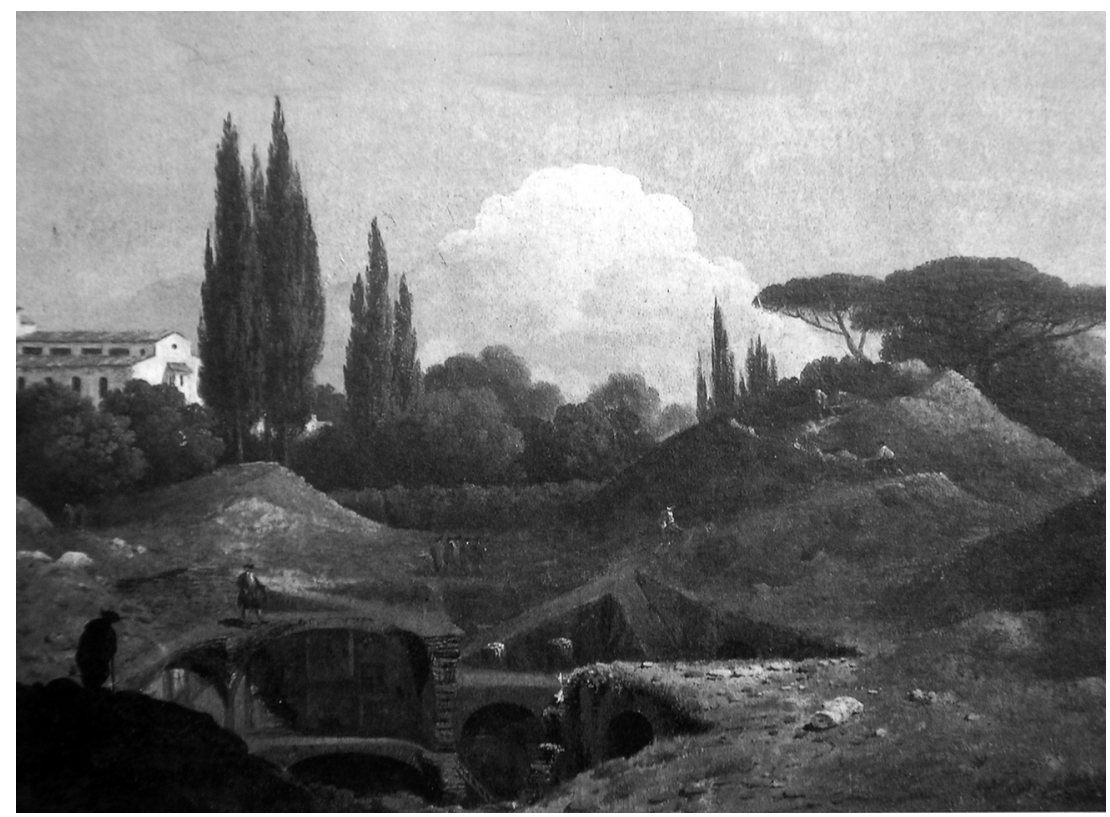

Fig. 9. Thomas Jones, An Antique Building discovered in a Cava in the Villa Negroni at Rome, 1779. Londres. Tate Gallery

El 2 de septiembre de 1777, día en que Pelham abandonaba Roma, escribía a Frederick Robinson lamentándose de tener que separarse del político aragonés, y le enviaba los saludos de éste y del pintor Mengs ${ }^{66}$.

64 Así se menciona en el Diario Ordinario Chracas de 19-7-1777, señalado en Carlo PIETRANGELI, Scavi e scoperte di antichità sotto il pontificato di Pio VI, Roma, 1958, p. 46.

65 Andew WILTON e Ilaria BIGNAMINI, Grand Tour ..., pp. 232-234 y n. 173; Ann SUMNER y Greg SMITH (eds.), Thomas Jones (1742-1803). An artist rediscovered, New Haven-Londres, 2003, pp. 175 y 176. Thomas Jones describió en su diario las «antiche stanze appena portate alla luce... Le pitture ornamentali di gusto cinese, con figure di Cupidi al bagno ecc., dipinte a fresco sullo stucco delle pareti. I rossi porpora, blu e gialli molto brillianti, ma di effetto scuro e pesante. I dipinti furono acquistati da Tresham che, per questi affreschi staccati dalle pareti a sue spese, offri 50 sterline». Cesare DE SETA, «Thomas Jones e i suoi Memoirs", en C. de SETA (ed.), Grand Tour. Viaggi narrati e dipinti, Nápoles, 2001, p. 94.

66 «I leave Rome this Evening with very great concern the Friendship of Azara with the many most interesting objects in this famous City have made me almost too fond of it». BLA, Manuscripts, L 30/15/42/13. Carta de Thomas Pelham a Frederick Robinson de 2 de septiembre de 1777. 
Finalizaremos añadiendo algunos nombres más a la lista de británicos que se cruzaron con Azara en la ciudad del Tíber. Por ejemplo, en 1774 le señalaba a su amigo y protector en el despertar de su carrera política, Manuel de Roda, los ceremoniales y etiquetas organizados en torno a la estancia en Roma del duque de Cumberland y su esposa, a los que asistía como mero espectador: el hermano del soberano Jorge III y su consorte fueron conducidos al Palacio de Monte Cavallo a fin de que lo visitaran a su placer con el pontífice ausente, se les llevó a admirar la cúpula de San Pedro iluminada, y recibieron el homenaje de la familia Borghese en sus posesiones de Frascati ${ }^{67}$. Doce años más tarde sería Azara quien ofreciera un convite en honor del matrimonio y su séquito, restándole protagonismo al papa Pío $\mathrm{VI}$, que había recibido a la real pareja en dos audiencias ${ }^{68}$.

Asimismo, tenemos constancia de un breve encuentro entre Azara y Sir John Macpherson (1744-1821), que trataba de olvidar sus amargas experiencias en el gobierno de la región de Bengala viajando por Europa ${ }^{69}$. A través de una misiva dirigida al conde de Floridablanca conocemos que en su segunda estancia en Roma (desde febrero de 1792) el ministro español lo invitó a unirse a él para almorzar juntos mientras estuviese en la ciudad, y aquél le comunicó sus planes de llegar a Nápoles, y desde allí a Gibraltar y España, por lo que damos por supuesto que Azara le proveería de las cartas de presentación necesarias y de sus inestimables consejos $^{70}$. El caballero inglés perdió a su acompañante en el sur de Italia, y salvo que tras la aventura hispana pretendía presentarse en Suiza, nada más sabemos del éxito de sus planes.

En ningún otro personaje de la Roma de la segunda mitad del siglo XVIII las citas laudatorias de Bourgoing y Castellanos de Losada habrían encontrado su sentido más que en la figura del polifacético José Nicolás de Azara. Su perspectiva del Grand Tour, más allá de la exploración de regiones pintorescas, de la recolección abusiva de obras de arte, o de la liberación de los yugos familiares que a menudo movían a los jóvenes ingleses, radicaba en una experiencia didáctica y de enriquecimiento personal impulsada por el sentimiento pedagógico de rellenar el vacío cultural, y prácticamente existencial, de sus visitantes: «Si no lo hago [de guía], mal lo pasarán los huéspedes, y quitarán la gana a otros paisanos de viajar y de instruirse», escribía Azara a propósito del recibimiento que dio en 1769 al conde de Villaseñor ${ }^{71}$. Plenamente consciente del papel que debía interpretar en la Ciudad Eterna, y del sentido último del «correr cortes» en la educación interna-

67 El espíritu..., vol. III, p. 28.

68 Diario Ordinario Chracas, 1.180, 22-4-1786, pp. 27 y 28.

69 John INGAMELLS, A Dictionary of British and Irish Travelers in Italy 1701-1800, New Haven y Londres, 1997, pp. 627 y 628.

70 Archivo Histórico Nacional. Estado. Leg. 3911. Carta de José Nicolás de Azara a José Moñino de 22 de febrero de 1792.

71 El espíritu..., vol. I, p. 328. Citado asimismo en Jean SARRAILH, La España ..., p. 373. Acerca del conde de Villaseñor continuaba Azara explicando la entrevista que mantuvo con el Papa, prácticamente un monólogo del noble español, «porque dice que ni para escupir se paró». 
cional de la juventud de su tiempo, reseñaba asimismo, con tono resignado, mas orgulloso, que «hago y haré mañana y tarde el cicerone, según mi destino para con todo español que pasa por aquí» 72 .

72 Estas palabras las anotó Azara cuando en el verano de 1773 el marqués de Llano se presentó en Roma con su esposa, la cual confió Azara a los cuidados de la princesa de Palestrina, ante sus dificultades en ejercer de guía de una mujer: «Es verdad que á mugeres no habia tenido que hacerlo [de cicerone] hasta ahora, porque esta es la primera española, que en mi tiempo se ha aparecido por aquí. Ruego á Dios que sea la última, porque no hallo el oficio cómodo». El espíritu..., vol II., pp. 422 y 423. 